\title{
The Comparison of General Health and Life Expectancy between Students with Favorable and Unfavorable Socioeconomic Status
}

\author{
Majid Saffarinia ${ }^{1}$, Fatemeh Amini ${ }^{2}$, \\ ${ }^{1}$ Department of Psychology, Tehran, PNU, Iran \\ *Corresponding Author: Fatemeh Amini, Ph.D. Student on Psychology, Department of Psychology, Tehran, PNU, Iran. \\ Email: f.amin83@gmail.com
}

\begin{abstract}
Introduction: The present study aims to compare general health and life expectancy between students with favorable and unfavorable socioeconomic status.

Methods: The statistical population in this study consists of all the students of Lamerd city in the second semester of the academic year of 20132014. The sample of this study consists of 200 male and female students. A hundred of them are in the favorable socioeconomic status and the other 100 are in the unfavorable socioeconomic status which were selected by multistage random sampling.

Results: The results of the analysis of MANOVA on the mean of life expectancy and general health scores indicated that there is a significant difference between the two groups regarding the investigated variables.

Conclusion: In general, given the vulnerability of people who are in low socioeconomic status compared to the other segments of the society, more attention should be paid to this issue by the authorities.

Keywords: Socio-Economic Status, General Health, Life Expectancy
\end{abstract}

Article History: Received: 11 Apr. 2015; Accepted: 26 Jul. 2015; Online Published: 26 Nov. 2015

Cite this article as: Saffarinia M, Amini F. The comparison of general health and life expectancy between students with favorable and unfavorable socioeconomic status. Int J Travel Med Glob Health. 2015;3(4):179-82.

\section{Introduction}

The socioeconomic status of the population that has a significant role in their health is the result of several factors. Due to the large differences in different populations and its deep and widespread influences from the society structure, deep-rooted cultural factors, social relations and policy governing, a precise and stable definition of this variable is not possible [1].

Commission of the World Health Organization [2] defines social determinants in a wider scope: "The social determinants of health are the circumstances in which people are born, grown up, live, work, and age, and the systems put in place to deal with illness. These circumstances are in turn shaped by a wider set of forces: economics, social policies, and politics". In different studies, socio-economic status are measured by several indicators, such as social class (based on employment), income, housing tenure, debt, financial problems and educational attainment [3].

The role of socio-economic factors in determining the overall health is widely accepted in the international community. Mental health is also not an exception. However, exactly where mental health, social and economic terms have to be set are complex and there are many features of socio-economic detriments of mental health that will distinguish it from other diseases. As a result, there is a growing international field of research devoted to the study of socio-economic factors of mental health and interventions that may be needed to show these factors to enhance community mental health [3]. Studies have shown that there is a range of psychological disorders related to low socioeconomic status. These disorders include schizophrenia, depression, substance misuse and personality disorders [4]. Empirical findings from developed countries show that for most mental health disorders, the relationship between low socio-economic status and psychiatric morbidity is strong and significant $[5,6]$.
The results of a meta-analysis of 51 studies of prevalence, 5 studies of incidence and 4 persistence studies, mostly from high-income countries, showed that people with low socioeconomic status are at greater risk of depression [7]. The findings of the study conducted by Bakhshi Soursajani [8] showed that there is a significant relationship between students' socio-economic status and depression. As a matter of a fact, there is a positive correlation between the variable of the number of members and students' depression, a negative correlation between father's education and depression and there is also a negative correlation between the variable of family income and depression.

One of the diagnostic criteria for depression is hopelessness [9]. Hopelessness which is a cognitive factor specified with negative expectations has a considerable role in depression [10].

The findings of the studies conducted by Akbarian, Rafie, Sajjadi and Karimlou [11] shows that there is a significant difference between unemployed people who use drugs and those in employment who are not addicted in terms of socioeconomic variables in operations of family income, per capita area of the home and subtracting the monthly family income from monthly rent by the number of family members and unemployed addicts who live in a lower socio-economic conditions have lower purpose and hope to the future than those who are not addicted.

Understanding the etiology of mental disorders is also necessary not only from the genetic or individual, but from a socio-economic perspective. Socio-economic factors play a major role in determining peoples' mental health, genetic and environmental factors interaction throughout one's life. On the other hand, its understanding opens opportunities for intervention at the community level. In particular, the understanding of socio-economic factors can improve mental health and prevent the primary and secondary level of mental illness, with the aim of reducing the socio- 
economic and health inequalities. Also, a better understanding of socio-economic factors can plan interventions more effectively and efficiently. Therefore, since the students and the youth of the country are the main assets and future manufacturers, paying attention to their mental state is of utmost importance.

The present study aims to survey whether there is a difference between students with favorable socioeconomic status and unfavorable socioeconomic status in terms of general health and life expectancy.

\section{Methods}

The research method in this study is causal-comparative. The statistical population in this study included all the students of Payam Noor University, Azad University and Tabnak in Lamerd city who were studying in the second half of the academic year of 2013-14. Initially, about 600 students in the multi-stage cluster sampling in terms of socioeconomic status were examined. Those who were not willing to continue to cooperate were excluded from the study, and finally 200 people (100 with favorable socioeconomic status and 100 with low socioeconomic status) responded to research tools. In order to analyze the data, multivariate analysis of variance (MANOVA) and the sixteenth edition of the SPSS software was used.

\subsection{Socio-economic Status}

This scale was designed for the first time in Iran by Garmaroudy and Moradi. In the study done by Garmaroudi and Moradi [1] in order to determine the reliability and weights of the variables that play a role in determining socioeconomic status at family levels, the mentioned variable were categorized into four categories. These categories included specifications of heads of households and his wife, costs and income, housing, facilities and leisure times. Creating various changes in the overall weights of each category of variables showed that in the most appropriate state, the reliability score of all questionnaire variables based on Cronbach's alpha indicator is 0.6 and this indicates that the correlation and cooperation of the designed tool variables is generally acceptable. The validity of the content of the questionnaires' questions were also investigated and revised by the opinion of related scholars which had an appropriate structural validity [1]. To determine the socio-economic class in a binary scale, the mass Likert scale method was used. For this reason, in order to determine the cut-off point, the value of the final factor obtained at the mean point which was zero was divided into two parts and was considered as the cut-off point. Its high amounts is considered appropriate and low amounts is considered inappropriate. In the present study, the research variables (general health and life expectancy) on 100 students was compared as favorable socioeconomic status and 100 students as unfavorable socioeconomic status.

\subsection{Life Expectancy Questionnaire}

This test consisted of 33 items which the subjects responded to it based on the Likert Scale (totally=3, almost $=2$ and never $=1$ ). The maximum score in the test was 99 and the minimum score was 33. The more score the subject achieved, the more hope it had for the future. Questions 1, 3, 7, 9, 10,11,12,13, 15.16, 17, 18, 20, 21, 24, 26,28 were graded in reverse. To determine the reliability of the questionnaire, Hallajian [12] conducted two Cronbach's alpha and test-retest methods which alpha coefficients was reported 0.89 and its reliability based on test-retest method was reported 0.80 in 4-6 week interval. The criteria question score was used to determine the validity. Therefore, the total scores were correlated with the criterion question score and it was determined that there is a significant positive relationship between the two. In the present study, the reliability coefficient of the scale in Cronbach's alpha method to the scale was calculated 0.84 .

\subsection{General Health Questionnaire}

The general health questionnaire designed by Goldberg in 1972, surveys one's mental state in the recent month. The questionnaire consists of 28 questions and has subscales such as physical health, anxiety and insomnia, social dysfunction and depression that has been scored by Likert scale from 0 3 (no, a little, high, very high). According to the cut-off point, obtaining a score higher than 23 in the total test indicates mental disorders and lower than it is a sign of mental health. In each area of physical health, depression, anxiety and social function, cut-off point 6 was used. The reliability of the questionnaire has been reported between 0.79 and 0.82 in the Iranian study. Also, in order to investigate the validity of the questionnaire, factor analysis was used. Results showed that GHQ factor structure has been made of four main factors, including depression, anxiety, social dysfunction and physical signs [13]. In the present study, the validity coefficient of this scale in Cronbach's alpha method for the general score of the scale was 0.92 GHQ and for physical subscale, 0.79, anxiety, 0.84, social function 0.70 and depression 0.84 .

\section{Results}

The present study aims to comparatively investigate general health and life expectancy between students with favorable and unfavorable socio-economic status. In this study, using cause-comparative research design and multivariate analysis of variance (MANOVA), data related to hypotheses of this research was statistically analyzed which were presented in two parts of descriptive findings and the ones related to hypotheses.

The descriptive findings of this study included statistical parameters such as mean, standard deviation and the number of participant subjects, which has been shown in Table 1 for all the variables studied in this research (general health and life expectancy).

The contents in Table 1 shows that the mean of students with unfavorable socioeconomic status in general health score is 36.65 , in favorable socioeconomic status, 18.36 and the mean of unfavorable socio-economic status in the score of life expectancy is 68.43 and in the group of socioeconomic status, it is calculated 79.76 .

At first, the assumptions of the homogeneity of variances was evaluated. As it can be seen in Table 2, the results of error variances homogeneity (Levine Test) shows that the variance of the error is not significant in the compared variables and therefore assumed homogeneity of variances is observed.

As shown in Table 3, there is a significant difference between the group of students with unfavorable socioeconomic status and favorable socio-economic status in terms of the variables compared at $\mathrm{P}<0.001$. Therefore, the research hypothesis is confirmed. Accordingly, it can be stated that there is a significant difference at least in one dependent variable between the two groups. 
Table 1. The mean, standard deviation, and number of participants in general health scale (and its components) and life expectancy.

\begin{tabular}{|c|c|c|c|c|}
\hline Group & Statistical indicators & Mean & Standard deviation & Number \\
\hline \multirow{5}{*}{$\begin{array}{l}\text { Students with } \\
\text { unfavorable } \\
\text { socioeconomic status }\end{array}$} & Total score of general health & 36.65 & 11.22 & 100 \\
\hline & Physical symptoms & 8.88 & 3.09 & 100 \\
\hline & Anxiety and insomnia & 9.96 & 4.09 & 100 \\
\hline & Depression & 8.76 & 4.44 & 100 \\
\hline & Life expectancy & 68.43 & 7.82 & 100 \\
\hline \multirow{6}{*}{$\begin{array}{l}\text { Students with favorable } \\
\text { socio-economic status }\end{array}$} & Total score of general health & 18.36 & 6.33 & 100 \\
\hline & Anxiety and insomnia & 4.90 & 4.01 & 100 \\
\hline & Physical symptoms & 4.44 & 3.24 & 100 \\
\hline & Social dysfunction & 5.87 & 2.75 & 100 \\
\hline & Depression & 3.15 & 4.14 & 100 \\
\hline & Life expectancy & 79.76 & 8.96 & 100 \\
\hline \multirow{4}{*}{ Total subjects } & Total score of general health & 27.50 & 14.99 & 200 \\
\hline & Physical symptoms & 6.66 & 3.86 & 200 \\
\hline & Anxiety and insomnia & 7.43 & 4.77 & 200 \\
\hline & Social dysfunction & 7.46 & 3.32 & 200 \\
\hline
\end{tabular}

In order to understand this difference, the dependent variables are examined in the next stage through AVONA in MANOVA text. These results have been shown in Table 4. As shown in Table 4, there is a significant difference between both groups in terms of the total score of general health $(\mathrm{F}=118.408, \mathrm{P}<0.001)$ and its subscales. Also, there is a significant difference between both groups in terms of life expectancy at the level of $(\mathrm{F}=90.759, \mathrm{P}<0.001)$. Therefore, general health and life expectancy of the students with favorable socio-economic status is higher.
Table 2. Results of error variances homogeneity (Levine Test)

\begin{tabular}{|lcccc}
\hline Levine & F & df1 & df2 & Significant level \\
\hline $\begin{array}{l}\text { Total score of general } \\
\text { health }\end{array}$ & 0.03 & 1 & 198 & 0.512 \\
\hline $\begin{array}{l}\text { Physical symptoms } \\
\text { Anxiety and insomnia }\end{array}$ & 0.43 & 1 & 198 & 0.895 \\
\hline Social dysfunction & 2.16 & 1 & 198 & 0.286 \\
\hline Depression & 1.14 & 1 & 198 & 0.867 \\
\hline Life expectancy & 1.44 & 1 & 198 & 0.232 \\
\hline
\end{tabular}

Table 3. Results achieved from MANOVA analysis on the mean of general health and life expectancy scores between students with favorable and unfavorable

\begin{tabular}{|c|c|c|c|c|c|}
\hline Effect & Value & $\mathbf{F}$ & Hypothesis df & Error df & Significant level \\
\hline Pillai's Trace & 0.302 & 28.39 & 5 & 194 & $<0.0001$ \\
\hline Wilk's Lambda & 0.698 & 28.39 & 5 & 194 & $<0.0001$ \\
\hline Hotelling's Trace & 0.432 & 28.39 & 5 & 194 & $<0.0001$ \\
\hline Roy's Largest Root & 0.432 & 28.39 & 5 & 194 & $<0.0001$ \\
\hline
\end{tabular}

Table 4. The results of ANOVA in the MANOVA text on the mean score of life expectancy, total score of general health and its subscales in students with favorable and unfavorable socio-economic status

\begin{tabular}{lcccc}
\hline \multicolumn{1}{c}{ Dependent Variable } & $\begin{array}{c}\text { Type III Sum of } \\
\text { Squares }\end{array}$ & df & Mean Square & Significant Level \\
\hline Total score of general health & 16725.651 & 1 & 16725.651 & \\
Physical symptoms & 985.680 & 1 & 985.680 & 118.408 \\
Anxiety and insomnia & 1280.180 & 1 & 1280.180 & 98.310 \\
Social dysfunctions & 505.620 & 1 & 505.620 & 78.020 \\
Depression & 1573.435 & 1 & 1573.435 & 59.518 \\
Life expectancy & 6414.654 & 1 & 6414.654 & 85.348 \\
\hline
\end{tabular}

\section{Discussion}

This study has aimed to compare general health and life expectancy between students with favorable and unfavorable socioeconomic status. The research results showed that there is a significant difference between the general health and life expectancy of students with favorable and unfavorable socio-economic status and general health and life expectancy of the students with low socio-economic status. The results are consistent with the results of other researches $[3,4,5,6,7,8,11]$.

In explaining these findings, it can be said that socioeconomic status may be weaker due to facing with stressful situations and deprivation $[14,15]$. Also, the lack of effective treatment will face health-related disorders [16]. On the other hand, people in low socioeconomic status are more vulnerable and are more likely to experience stressful experiences, such as exposure to violence and poorer physical health that is known as a risk factor for mental health disorders [17].

The students who live in families with high and optimal incomes use existing facilities and are usually less concerned about the future. For example, parents with higher education are aware of the needs of their children and try to deal with them in proportionate with their mood. Poor environment is led to reduce parental support physically and materially and converts a mild problems to severe mental and physical disorders. People with low socio-economic status find a series of shortcomings in their lives. Therefore, lower socioeconomic status provides a situation for a depressed mood, and also people follow negative life events in depressed moods. According to Iron Beck's theory, their belief about themselves, the world and their future is negative and understanding this will cause them despair. 


\section{Conclusions}

In general, given the vulnerability of people who are in low socioeconomic status compared to the other segments of the society, more attention should be paid to this issue by the authorities. The problems of this group of the society is obviated to some extent by flexible preventive methods that help guide personality, educational and occupational issues and thus the self-sufficiency in individuals is influenced by using these methods. Also, credit is devoted to educational programs, job creation by various projects, especially in the treatment sector which will be helpful in solving the problem.

\section{Acknowledgements}

Authors would like to thank Mohtaram Delnavaz for his assistance with the data collection.

\section{Authors' Contributions}

The authors were involved in the study design, data collection, interpretation of the results, and preparation of the manuscript.

\section{Funding/Support}

None received.

\section{Financial Disclosure}

The authors declared no financial disclosure.

\section{References}

1. Garmaroudi G, Moradi A. Socio-economic status in Iran: a study of measurement index. Payesh. 2010;9(2):137-44. Persian

2. WHO. Closing the gap in a generation: Health equity through action on the social determinants of health. Geneva: WHO, 2008.

3. Loud C, Stansfeld S, Silva MD. Social Determinants of Mental Health. In Patel W, Minas H, Cohen A, Prince MJ. (Eds.), Global: Mental Health: Principle and Practice. Oxford University Press. 2014:116-36

4. Dohrenwend BP, Levav I, Shrout PE, et al. Socioeconomic status and psychiatric disorders: the causation-selection issue. Science 1992;255(5047):946-52.

5. Kessler RC, Chiu WT, Demler O, Walters EE. Prevalence, severity, and comorbidity of 12-month DSM-IV disorders in the National Comorbidity Survey Replication. Arch Gen Psychiatry. 2005;62(6):617-27.

6. WHO International Consortium in Psychiatric Epidemiology. Crossnational comparisons of the prevalence's and correlates of mental disorders. Bull WHO. 2000;78(4):413-26.

7. Lorant V, Deliege D, Eaton W, Robert A, Philippot P, Ansseau M. Socio-economic inequalities in depression: a meta-analysis. Am J Epidemiol. 2003;157:98-112.

8. Bakhshi Soureshjani L. Relationship between perfectionism and depression and academic performance and the relationship between two recent variables with socio-economic status of students of Islamic Azad Universit, Behbehan Branch. Educ J Islamic Azad Univ Bojnourd Branch. 2010;19:37-60.

9. Sadock B, Sadock V. Summary of Psychiatry (Volume II): Behavioral Sciences-Clinical Psychiatry, translated by Rafie, Hassan and Sobhanian, Khosrou, Tehran, Arjmand Publications, 2008: 118. Persian

10. Chioqueta AP, Stiles TC. Personality traits and the development of depression, hopelessness, and suicide ideation. Pers Individ Dif. 2005;38:1283-91

11. Akbarian M, Rafie H, Sajjadi H, Karimlou M. Socio-economic status, religious behaviors, and life expectancy, predictor of drug use among the unemployed health. J Ardabil Univ Med Sci. 2010;1(1):47-56. Persian

12. Hallajian Z. Relationship between life expectancy, happiness and quality of life in patients with thalassemia compared to the general population at the city of Ramsar in 2007. BA Thesis. PNU Ramsar Center, 2009. Persian

13. Taghavi, M. Validity and reliability of mental health questionnaire. J Psychol. 2002;5:381-97.

14. Johnson JG, Cohen P, Dohrenwend BP, Link BG, Brook JSA longitudinal investigation of social causation and social selection processes involved in the association between socioeconomic status and psychiatric disorders. J Abnorm Psy. 1999;108(3):490-99.

15. Miech RA, Caspi A, Moffitt TE, Wright BRE, Silva PA. Low socioeconomic status and mental disorders: A longitudinal study of selection and causation during young adulthood. Am J Sociol. 1999;104(4):1096-131

16. WHO. The World Health report - mental health: New understanding, new hope. WHO, 2001.

17. Patel V, Kleinman A. Poverty and common mental disorders in developing countries. Bull WHO. 2003;81(8):609-15. 